\title{
Mathematical Modelling and Simulation for One Dimensional - Two-Phase Flow Equation in Petroleum Reservoir: A Matlab Algorithm Approach
}

\author{
JWNGSAR BRAHMA \\ Pandit Deendayal Energy University \\ Gandhinagar - 382007, Gujarat \\ INDIA
}

\begin{abstract}
The reservoir behaviors described by a set of differential equation those results from combining Darcy's law and the law of mass conservation for each phase in the system. The one-dimensional two-phase flow equation is implicit in the pressure and saturation and explicit in relative permeability. A mathematical model of a physical system is a set of partial differential equations together with an appropriate set of boundary conditions, which describes the significant physical processes taking place in that system. The processes occurring in petroleum reservoirs are fluid flow and mass transfer. Two immiscible phases (water\& oil) flow simultaneously while mass transfer may take place among the phases. Gravity, capillary, and viscous forces play a role in the fluid-flow process. The model equations must account for all these forces and should also take into account an arbitrary reservoir description with respect to heterogeneity and geometry. Finally, one-dimensional two-phase flow equation through porous media is formulated by considering above reservoir parameters and forces.
\end{abstract}

A numerical method based on finite difference scheme is implemented to get the solutions of one-dimensional twophase flow equation. A MATLAB algorithm is used to solve the equation with mathematical analysis resulting in upper and lower bounds for the ratio of time step to mesh. The MATLAB algorithm is modified as per the model with appropriate initial and boundary conditions. The algorithm is applied to two-phase water flooding problems in laboratory size cores, and resulting saturation and pressure distribution are presented graphically. The saturation and pressure distribution of two-phase flow model is in agreement with the prediction of the Buckley Leveret theory.

The numerical solution is used as a base for evaluating the numerical methods with respect to machine time requirement and allowable tie step for fixed mesh spacing.

Keywords: Mathematical modeling, one-dimensional two-phase flow, numerical solution, MATLAB algorithm.

Received: May 28, 2021. Revised: September 30, 2021. Accepted: October 10, 2021. Published: October 29, 2021.

\section{Introduction}

It should be very clear that the different reservoir flow problems can be highly complex, consisting of a multitude of different physical effects. Including the water reservoir. Water is the most important component of maintaining life after air [3]. However, an understanding is necessary so that different production scenario and reservoir interpretations may be tested. To some, degree, this can be done by laboratory experiment, but these cannot be very large and tend to be expensive to conduct. Instead, the use of mathematical models has been progressively more prominent in reservoir flow problems using simple mathematical models with the analytical solution; the engineer can provide basic performance predictions. However, for the more advanced models, analytical answers may not be available. Instead, numerical methods for simulating the models have become popular, especially with the advent of fast computers.
But there are still trade of this. In particular, the more detailed the mathematical model, the slower the computer can calculate the solution. Therefore we must seek fast numerical scheme combined with suitable mathematical models for the reservoir. And even the geological descriptions of the reservoir may be riddled with uncertainty, leading us to perform multiple realizations and model calibrate based on production data.

There are four major stages of the modeling and simulation process. First, a physical model of the flow processes must be developed incorporating as much as geology, biology, chemistry, and physics as is deemed necessary to describe the essential phenomena. Second, a mathematical formulation of the physical model must be obtained, usually involving coupled systems of nonlinear, time-dependent partial differential equations. The analyses of these systems of differential equations are often quite complex mathematically. Third, once the properties of the mathematical model, such as existence, 
uniqueness, and regularity of the solution, are sufficiently well understood, a discredited numerical model of the mathematical equation for the physical model must be produced. A numerical model is determined that has the required properties of accuracy and stability and which produces solutions representing the basic physical features as well as possible, without introducing spurious phenomena associated with the specific numerical approximations [1]. Finally, a computer program capable of efficiently performing the necessary computations for the numerical model is developed. Mathematical model and simulations play very important roles nowadays for the prediction of future events [4].

The total modeling process encompasses aspects of each of these four intermediate steps, which are clearly coupled in many ways. This involves the multidisciplinary of a wide variety of scientists. Thus the effective simulation of these problems should involve the collaboration of scientists, often across disciplines and institutions, to address the enormous complexity of these models.

Finally, the modeling process is not complete with one pass through four steps. Once a computer code has been developed which gives a concrete quantitative result for the total model, this output should be compared with corresponding measured observations of the physical process. If the results do not compare extremely well, one should iterate back through complete modeling process, changing the various intermediate models in ways to obtain better correlations between the physical measurements from the laboratory or field and computational results. Often many iterations of this modeling loop are necessary to obtain reasonable models for the highly complex physical phenomena describing contaminants remediation processes.

In this paper a one-dimensional, two-phase flow equation through heterogeneous porous media and imposing appropriate initial and boundary conditions is developed. A finite difference schemes is developed to solve the partial differential equation along with analysis with the help of the MATLAB algorithm. Finally a water saturation profiles and pressure profiles were developed from the model incorporation with capillary pressure effect due to the wetting phase and the nonwetting phase [2].

\section{Mathematical Model Formulation}

\section{and Problem Statement}

Consider a one-dimensional system in which gravity and molecular diffusion are negligible. If $\mathrm{n}$ immiscible phases are present, n: the equation describing the flow of the $\mathrm{i}^{\text {th }}$ phase is:

$$
-\frac{\partial\left(\alpha \rho_{i} v_{i}\right)}{\partial x}=\alpha \frac{\partial\left(\varnothing \rho_{i} \mathrm{~S}_{i}\right)}{\partial t}
$$

Here, we take two-phase as wetting phase and nonwetting phase as follow:

For nonwetting phase

$$
-\frac{\partial\left(\alpha \rho_{n} v_{n}\right)}{\partial x}=\alpha \frac{\partial\left(\varnothing \rho_{n} S_{n}\right)}{\partial t}
$$

And for wetting phase

$$
-\frac{\partial\left(\alpha \rho_{w} v_{w}\right)}{\partial x}=\alpha \frac{\partial\left(\emptyset \rho_{w} S_{w}\right)}{\partial t}
$$

By combining equation with the equation, we obtain the set of simultaneous differential equations that describe two-phase flow:

$$
\begin{aligned}
& -\frac{\partial}{\partial x}\left[\frac{\alpha \rho_{n} K k_{r n}}{\mu_{n}}\left(\nabla p_{n}-\rho_{n} g \nabla D\right)\right]= \\
& \alpha \frac{\partial\left(\emptyset \rho_{n} S_{n}\right)}{\partial \mathrm{t}} \\
& -\frac{\partial}{\partial \mathrm{x}}\left[\frac{\alpha \rho_{\mathrm{w}} \mathrm{Kk}_{\mathrm{rw}}}{\mu_{\mathrm{w}}}\left(\nabla \mathrm{p}_{\mathrm{w}}-\rho_{\mathrm{w}} \mathrm{g} \nabla \mathrm{D}\right)\right]= \\
& \alpha \frac{\partial\left(\varnothing \rho_{\mathrm{w}} \mathrm{s}_{\mathrm{w}}\right)}{\partial \mathrm{t}}
\end{aligned}
$$

These equations are extremely general in their applicability, including, as they do, the effects of capillary pressure and relative permeability, as well as variations with the position of the absolute permeability and porosity.

Now, we neglecting the gravity effect on the flow and put the value $\nabla D=0$ for the horizontal flow; and also taking the one dimensional pressure change, so

$$
\nabla p=\frac{\partial p}{\partial x}
$$

So, we get the equation,

$$
\begin{aligned}
& -\frac{\partial}{\partial x}\left[\frac{\alpha \rho_{n} K k_{r n}}{\mu_{n}}\left(\frac{\partial p_{n}}{\partial x}\right)\right]=\alpha \frac{\partial\left(\emptyset \rho_{n} S_{n}\right)}{\partial \mathrm{t}} \\
& -\frac{\partial}{\partial \mathrm{x}}\left[\frac{\alpha \rho_{\mathrm{w}} \mathrm{Kk} \mathrm{k}_{\mathrm{rw}}}{\mu_{\mathrm{w}}}\left(\frac{\partial p_{w}}{\partial x}\right)\right]=\alpha \frac{\partial\left(\varnothing \rho_{\mathrm{w}} \mathrm{S}_{\mathrm{w}}\right)}{\partial \mathrm{t}}
\end{aligned}
$$

By differentiating equation 3.4(a) and 3.4(b),

$$
-\frac{\alpha \rho_{\mathrm{n}} K \mathrm{k}_{\mathrm{rn}}}{\mu_{\mathrm{n}}} \frac{\partial}{\partial \mathrm{x}}\left(\frac{\partial \mathrm{p}_{\mathrm{n}}}{\partial \mathrm{x}}\right)-\left(\frac{\partial \mathrm{p}_{\mathrm{n}}}{\partial \mathrm{x}}\right) \frac{\partial}{\partial \mathrm{x}}\left[\frac{\alpha \rho_{\mathrm{n}} K \mathrm{k}_{\mathrm{rn}}}{\mu_{\mathrm{n}}}\right]=\alpha \frac{\partial\left(\varnothing \rho_{\mathrm{n}} \mathrm{S}_{\mathrm{n}}\right)}{\partial \mathrm{t}}
$$

$$
-\frac{\alpha \rho_{\mathrm{n}} \mathrm{Kk}_{\mathrm{rw}}}{\mu_{\mathrm{w}}} \frac{\partial}{\partial \mathrm{x}}\left(\frac{\partial \mathrm{p}_{\mathrm{w}}}{\partial \mathrm{x}}\right)-\left(\frac{\partial \mathrm{p}_{\mathrm{w}}}{\partial \mathrm{x}}\right) \frac{\partial}{\partial \mathrm{x}}\left[\frac{\alpha \rho_{\mathrm{w}} \mathrm{Kk}_{\mathrm{rw}}}{\mu_{\mathrm{w}}}\right]=\alpha \frac{\partial\left(\phi \rho_{\mathrm{n}} \mathrm{S}_{\mathrm{n}}\right)}{\partial \mathrm{t}}
$$




$$
\begin{aligned}
& -\frac{\alpha \rho_{\mathrm{n}} \mathrm{Kk}_{\mathrm{rn}}}{\mu_{\mathrm{n}}}\left(\frac{\partial^{2} \mathrm{p}_{\mathrm{n}}}{\partial \mathrm{x}^{2}}\right)- \\
& \left(\frac{\partial \mathrm{p}_{\mathrm{n}}}{\partial \mathrm{x}}\right) \frac{\partial}{\partial \mathrm{x}}\left[\frac{\alpha \rho_{\mathrm{n}} \mathrm{Kk}_{\mathrm{rn}}}{\mu_{\mathrm{n}}}\right]=\alpha \frac{\partial\left(\varnothing \rho_{\mathrm{n}} \mathrm{S}_{\mathrm{n}}\right)}{\partial \mathrm{t}} \\
& -\frac{\alpha \rho_{\mathrm{w}} \mathrm{Kk}_{\mathrm{rw}}}{\mu_{\mathrm{w}}}\left(\frac{\partial^{2} \mathrm{p}_{\mathrm{w}}}{\partial \mathrm{x}^{2}}\right)- \\
& \left(\frac{\partial \mathrm{p}_{\mathrm{w}}}{\partial \mathrm{x}}\right) \frac{\partial}{\partial \mathrm{x}}\left[\frac{\alpha \rho_{\mathrm{w}} \mathrm{Kk}_{\mathrm{rw}}}{\mu_{\mathrm{w}}}\right]=\alpha \frac{\partial\left(\varnothing \rho_{\mathrm{w}} \mathrm{S}_{\mathrm{w}}\right)}{\partial \mathrm{t}}
\end{aligned}
$$

Now, the ratio of the density to the viscosity varies with fluid for wetting and nonwetting, both phases. So, assume that the relation between the ratio of density to the viscosity; of the wetting and nonwetting phases are given as,

$\frac{\rho_{\mathrm{w}}}{\mu_{\mathrm{w}}}=\gamma \frac{\rho_{\mathrm{n}}}{\mu_{\mathrm{n}}}$

But assume $\gamma=1$

$$
\begin{aligned}
& \frac{\rho_{\mathrm{w}}}{\mu_{\mathrm{w}}}=\frac{\rho_{\mathrm{n}}}{\mu_{\mathrm{n}}}=\frac{\rho}{\mu} \\
& -\frac{\alpha \rho \mathrm{Kk}_{\mathrm{rn}}}{\mu_{\mathrm{n}}}\left(\frac{\partial^{2} \mathrm{p}_{\mathrm{n}}}{\partial \mathrm{x}^{2}}\right)+ \\
& \left(\frac{\partial \mathrm{p}_{\mathrm{n}}}{\partial \mathrm{x}}\right) \frac{\partial}{\partial \mathrm{x}}\left[-\frac{\alpha \rho \mathrm{Kk}_{\mathrm{rn}}}{\mu_{\mathrm{n}}}\right]=\alpha \frac{\partial\left(\emptyset \rho_{\mathrm{n}} \mathrm{S}_{\mathrm{n}}\right)}{\partial \mathrm{t}} \\
& -\frac{\alpha \rho \mathrm{Kk}_{\mathrm{rw}}}{\mu_{\mathrm{w}}}\left(\frac{\partial^{2} \mathrm{p}_{\mathrm{w}}}{\partial \mathrm{x}^{2}}\right)+ \\
& \left(\frac{\partial \mathrm{p}_{\mathrm{w}}}{\partial \mathrm{x}}\right) \frac{\partial}{\partial \mathrm{x}}\left[-\frac{\alpha \rho \mathrm{Kk}_{\mathrm{rw}}}{\mu_{\mathrm{w}}}\right]=\alpha \frac{\partial\left(\varnothing \rho_{\mathrm{w}} \mathrm{S}_{\mathrm{w}}\right)}{\partial \mathrm{t}}
\end{aligned}
$$

Now assume,

$$
-\frac{\alpha \rho \mathrm{Kk}_{\mathrm{rn}}}{\mu_{\mathrm{n}}}=-\frac{\alpha \rho \mathrm{Kk} \mathrm{r}_{\mathrm{rw}}}{\mu_{\mathrm{w}}}=\mathrm{A}_{\mathrm{r}}
$$

So,

$$
\begin{aligned}
& \frac{\partial}{\partial \mathrm{x}}\left[-\frac{\alpha \rho \mathrm{Kk}_{\mathrm{rn}}}{\mu_{\mathrm{n}}}\right]=\frac{\partial}{\partial \mathrm{x}}\left[-\frac{\alpha \rho \mathrm{Kk}_{\mathrm{rw}}}{\mu_{\mathrm{w}}}\right]=\frac{\partial}{\partial \mathrm{x}}\left(\mathrm{A}_{\mathrm{r}}\right)=\mathrm{B}_{\mathrm{r}} \\
& \mathrm{A}_{\mathrm{r}}\left(\frac{\partial^{2} \mathrm{p}_{\mathrm{n}}}{\partial \mathrm{x}^{2}}\right)+\mathrm{B}_{\mathrm{r}}\left(\frac{\partial \mathrm{p}_{\mathrm{n}}}{\partial \mathrm{x}}\right) \\
& =\alpha \frac{\partial\left(\varnothing \rho_{\mathrm{n}} \mathrm{S}_{\mathrm{n}}\right)}{\partial \mathrm{t}} \\
& \mathrm{A}_{\mathrm{r}}\left(\frac{\partial^{2} \mathrm{p}_{\mathrm{w}}}{\partial \mathrm{x}^{2}}\right)+\mathrm{B}_{\mathrm{r}}\left(\frac{\partial \mathrm{p}_{\mathrm{w}}}{\partial \mathrm{x}}\right)=\alpha \frac{\partial\left(\varnothing \rho_{\mathrm{w}} \mathrm{S}_{\mathrm{w}}\right)}{\partial \mathrm{t}}
\end{aligned}
$$

Subtracting equation 2.8(a) and 2.8(b),

$$
\begin{aligned}
& \mathrm{A}_{\mathrm{r}}\left[\left(\frac{\partial^{2} \mathrm{p}_{\mathrm{n}}}{\partial \mathrm{x}^{2}}\right)-\left(\frac{\partial^{2} \mathrm{p}_{\mathrm{w}}}{\partial \mathrm{x}^{2}}\right)\right]+ \\
& \mathrm{B}_{\mathrm{r}}\left[\left(\frac{\partial \mathrm{p}_{\mathrm{n}}}{\partial \mathrm{x}}\right)-\left(\frac{\partial \mathrm{p}_{\mathrm{w}}}{\partial \mathrm{x}}\right)\right]=\alpha\left[\frac{\partial\left(\varnothing \rho_{\mathrm{n}} \mathrm{S}_{\mathrm{n}}\right)}{\partial \mathrm{t}}-\right. \\
& \left.\frac{\partial\left(\varnothing \rho_{\mathrm{w}} \mathrm{S}_{\mathrm{w}}\right)}{\partial \mathrm{t}}\right]
\end{aligned}
$$

But we know that,

\section{capillary pressure}

$$
=\text { pressure of non wetting phase }
$$$$
\text { - pressure of wetting phase }
$$

$$
p_{c}=p_{n}-p_{w}
$$

Differentiate both sides with respect to $\mathrm{x}$,

$$
\left(\frac{\partial p_{c}}{\partial x}\right)=\left(\frac{\partial p_{n}}{\partial x}\right)-\left(\frac{\partial p_{w}}{\partial x}\right)
$$

And one more time differentiate equation with respect to $\mathrm{x}$, then we get

$$
\left(\frac{\partial^{2} p_{c}}{\partial x^{2}}\right)=\left(\frac{\partial^{2} p_{n}}{\partial x^{2}}\right)-\left(\frac{\partial^{2} p_{w}}{\partial x^{2}}\right)
$$

By equation 2.9, 2.10 and 2.11 we obtain that,

$$
\begin{gathered}
\left.\begin{array}{c}
k_{i}= \\
\left(S_{i}-S_{i}^{*}\right)^{a} f_{i}\left(S_{1}, S_{2}, \ldots, S_{n}\right), S_{i}>S_{i}^{*} \\
0, S_{i}<S_{i}^{*}
\end{array}\right\} \\
\mathrm{A}_{\mathrm{r}\left(\frac{\partial^{2} p_{c}}{\partial x^{2}}\right)+\mathrm{B}_{\mathrm{r}}\left(\frac{\partial p_{c}}{\partial x}\right)=} \\
\alpha\left[\frac{\partial\left(\varnothing \rho_{n} S_{n}\right)}{\partial \mathrm{t}}-\frac{\partial\left(\varnothing \rho_{w} S_{w}\right)}{\partial \mathrm{t}}\right]
\end{gathered}
$$

We assume an independent term $A_{r}$ which is indirectly ratio of permeability to viscosity and in addition, we predict another term $\mathrm{Br}$ that is the derivative of the $\mathrm{A}_{\mathrm{r}}$.

Now,

$$
\frac{\partial p_{c}}{\partial x}=\mathrm{R}_{\mathrm{c}}
$$

Where $R_{c}$ is the pressure gradient or change in pressure with respect to the length

$$
\begin{aligned}
& \mathrm{A}_{\mathrm{r}}\left(\frac{\partial \mathrm{R}_{\mathrm{c}}}{\partial x}\right)+\mathrm{B}_{\mathrm{r}}\left(\mathrm{R}_{\mathrm{c}}\right)=\alpha\left[\frac{\partial\left(\emptyset \rho_{n} S_{n}\right)}{\partial \mathrm{t}}-\right. \\
& \left.\frac{\partial\left(\emptyset \rho_{w} S_{w}\right)}{\partial \mathrm{t}}\right]
\end{aligned}
$$

But $A_{r}$ here is,

$-\frac{\alpha \rho K k_{r w}}{\mu_{\mathrm{w}}}=A_{r}$

this expression will always have a negative numerator and a positive denominator (at least one pair of the $A_{i}$ and $B_{i}$ must be non-zero) and hence $q(x, t)$ will always be negative.

And further taking its derivative, we found $\frac{\partial}{\partial \mathrm{x}}\left[-\frac{\alpha \rho \mathrm{Kk}_{\mathrm{rw}}}{\mu_{\mathrm{w}}}\right]=\mathrm{B}_{\mathrm{r}}$

Putting the value of both $A_{r}$ and $B_{r}$ in previous equation 3.13 , following set of equations are obtained 


$$
\begin{aligned}
& \left(-\frac{\alpha \rho K k_{r w}}{\mu_{\mathrm{w}}}\right)\left(\frac{\partial \mathrm{R}_{\mathrm{c}}}{\partial x}\right)+ \\
& \frac{\partial}{\partial \mathrm{x}}\left[-\frac{\alpha \rho \mathrm{Kk}_{\mathrm{rw}}}{\mu_{\mathrm{w}}}\right]\left(\mathrm{R}_{\mathrm{c}}\right)=\alpha\left[\frac{\partial\left(\varnothing \rho_{n} S_{n}\right)}{\partial \mathrm{t}}-\right. \\
& \left.\frac{\partial\left(\varnothing \rho_{w} S_{w}\right)}{\partial \mathrm{t}}\right]
\end{aligned}
$$

For simplifying above equation, we cancel the alpha $(\alpha)$ a geometric factor and function of length $\mathrm{x}, \mathrm{y}, \mathrm{z}$.

$$
\begin{aligned}
& \left(\frac{\rho K k_{r w}}{\mu_{\mathrm{w}}}\right)\left(\frac{\partial \mathrm{R}_{\mathrm{c}}}{\partial x}\right)+\frac{\partial}{\partial \mathrm{x}}\left[\frac{\rho \mathrm{Kk}_{\mathrm{rw}}}{\mu_{\mathrm{w}}}\right]\left(\mathrm{R}_{\mathrm{c}}\right)= \\
& \varnothing\left[\frac{\partial\left(\rho_{w} S_{w}\right)}{\partial \mathrm{t}}-\frac{\partial\left(\emptyset \rho_{n} S_{n}\right)}{\partial \mathrm{t}}\right]
\end{aligned}
$$

After solving this we reach to the above equation as shown here.

It is assumed that the space-time histories of $P_{i}$ and $\mu_{i}$ are either known a priori, or can be calculated through the use of appropriate equations. Furthermore, it is postulated that:

Where, $\mathrm{i}=1,2, \ldots, \mathrm{n}$; $\mathrm{a}$ is a positive integer and $S_{i}^{*}$ is a constant $>0$. Hence, equation represents a system of 2 simultaneous, nonlinear partial differential equations in 3 unknowns $\left(S_{n}, S_{w}\right.$ and $\left.p_{c}\right)$.

The problem statement is completed by specifying the additional condition:

$$
\sum_{i=1}^{n} S_{i}=1, \quad \mathrm{i}=1,2, \ldots, \mathrm{n}
$$

Together with the physical constraints:

$$
0 \leq S_{i} \leq 1, \quad \mathrm{i}=1,2, \ldots, \mathrm{n}
$$

But here we consider only two phase as wetting and nonwetting phase, so we have only two saturation values as $S_{n}$ and $S_{w}$.

\section{Initial and Boundary Conditions}

Equations 2.12 to 2.15 will be solved in a finite spaceinfinite time domain, with initial conditions specified at $\mathrm{t}=0$ and boundary conditions specified at $\mathrm{x}=0$ and $\mathrm{x}=$ $\mathrm{L}$ (inlet and outlet ends, respectively).

The initial conditions are [1]:

$$
\begin{aligned}
& S_{i}(x, 0)=g_{i}(x), \quad \mathrm{i}= \\
& 1,2, \ldots, \mathrm{n}
\end{aligned}
$$

and the condition at the outlet end of the system is:

$$
\rho(L, t)=\text { constant }
$$

The inlet condition, which describes a constant mass injection rate, is:

$$
G_{i}=-\left.\frac{\rho_{i} k_{i}}{\mu_{i}} \frac{\partial p}{\partial x}\right|_{x=0}=\text { constant }
$$

Where $G_{i}$ is the inlet mass flux in the ith phase.
In general, the use of Eq. 2.19 allows $S_{i}(0, t)$ and $\left.\frac{\partial p}{\partial x}\right|_{x=0}$ to vary with time in such a manner that Eqs. 2.17 and 2.18 are satisfied. If only the $j^{\text {th }}$ phase is injected, however, then $G_{i}$ and $S_{i}(x, 0)$ equal zero for $i \neq j$ and Eq. 2.19 can be replaced by:

$$
\begin{gathered}
S_{j}(0, t)=1 \\
\left.\frac{\partial p}{\partial x}\right|_{x=0}=-\frac{G_{j} \mu_{j}}{\rho_{j} k_{j}}=\text { constant }
\end{gathered}
$$

If any of the densities or viscosities is pressuredependent functions, it is necessary to specify, in addition, an initial pressure distribution:

$$
p(x, 0)=h(x)
$$

These conditions are sufficient to allow particular solutions of the above system of equations. Two numerical methods are presented for solving these equations.

\section{Numerical solution}

\subsection{Explicit method}

The explicit method is stated clearly in details and calculates the status of a system for a future time from the current known system process for confined and assured results.

As

$$
\mathrm{Y}=\mathrm{F}(\mathrm{y}, \mathrm{t})
$$

By the explicit method,

$$
Y_{n+1}=Y_{n}+\mathrm{h}_{\mathrm{f}} F\left(Y_{n}, t_{n}\right)
$$

For the explicit method, we need to carry some of the easy steps to facilitate further program by consuming very less time. On contrary, its stability is too low so we need to use enough small step size to prevent divergence.

Another drawback of the explicit method is that even for non-linear equation it is quite a tough task to get positive results for the same.

$$
\begin{aligned}
& \left(\frac{\rho K k_{r w}}{\mu_{\mathrm{w}}}\right)\left(\frac{\partial \mathrm{R}_{\mathrm{c}}}{\partial x}\right)+\frac{\partial}{\partial \mathrm{x}}\left[\frac{\rho \mathrm{Kk}_{\mathrm{rw}}}{\mu_{\mathrm{w}}}\right]\left(\mathrm{R}_{\mathrm{c}}\right)= \\
& \varnothing\left[\frac{\partial\left(\rho_{w} S_{w}\right)}{\partial \mathrm{t}}-\frac{\partial\left(\varnothing \rho_{n} S_{n}\right)}{\partial \mathrm{t}}\right]
\end{aligned}
$$

This approximation neglects the change in density over a given time step, which can be important for some 
problems. The finite-difference formulation still allows for a spatial variation in the density, however, so that the problem is not quite that of strictly incompressible flow. Density distribution can vary from one time step to another as the pressure changes. In this sense, change in density with time is treated as a succession of steady state.

By applying the explicit method the further step is to convert it in the discrete form.

Hence the discrete form of equation obtained is

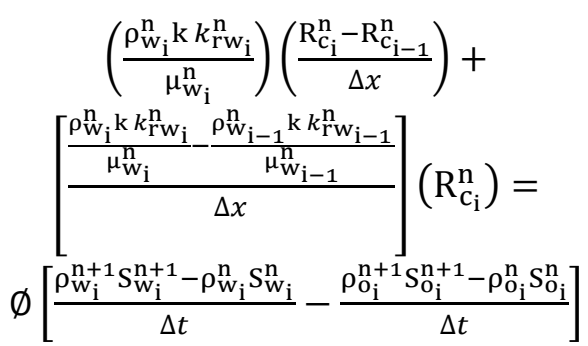

$$
\begin{aligned}
& \frac{1}{\Delta \mathrm{x}}\left\{\left(\frac{\rho_{\mathrm{w}_{\mathrm{i}}}^{\mathrm{n}} \mathrm{k} \mathrm{k}_{\mathrm{r}}^{\mathrm{n}} \mathrm{w}_{\mathrm{i}}}{\mu_{\mathrm{w}_{\mathrm{i}}}^{\mathrm{n}}}\right)\left(\mathrm{R}_{\mathrm{c}_{\mathrm{i}}}^{\mathrm{n}}-\mathrm{R}_{\mathrm{c}_{\mathrm{i}-1}}^{\mathrm{n}}\right)+\left[\frac{\rho_{\mathrm{w}_{\mathrm{i}}}^{\mathrm{n}} \mathrm{k} \mathrm{k}_{\mathrm{r}}^{\mathrm{n}} \mathrm{w}_{\mathrm{i}}}{\mu_{\mathrm{w}_{\mathrm{i}}}^{\mathrm{n}}}-\right.\right. \\
& \left.\left.\frac{\rho_{\mathrm{w}_{\mathrm{i}-1}}^{\mathrm{n}} \mathrm{k} \mathrm{k}_{\mathrm{rw}_{\mathrm{i}-1}}^{\mathrm{n}}}{\mu_{\mathrm{w}_{\mathrm{i}-1}}^{\mathrm{n}}}\right]\left(\mathrm{R}_{\mathrm{c}_{\mathrm{i}}}^{\mathrm{n}}\right)\right\}= \\
& \frac{1}{\Delta \mathrm{t}}\left\{\varnothing \left[\rho_{\mathrm{w}_{\mathrm{i}}}^{\mathrm{n}+1} S_{\mathrm{w}_{\mathrm{i}}}^{\mathrm{n}+1}-\rho_{\mathrm{w}_{\mathrm{i}}}^{\mathrm{n}} \mathrm{S}_{\mathrm{w}_{\mathrm{i}}}^{\mathrm{n}}-\right.\right. \\
& \left.\left.\rho_{\mathrm{o}_{i}}^{\mathrm{n}+1} S_{\mathrm{O}_{i}}^{\mathrm{n}+1}+\rho_{\mathrm{o}_{\mathrm{i}}}^{\mathrm{n}} S_{\mathrm{o}_{i}}^{\mathrm{n}}\right]\right\}
\end{aligned}
$$

$$
\begin{aligned}
& \frac{\Delta \mathrm{t}}{\Delta \mathrm{x}}=
\end{aligned}
$$

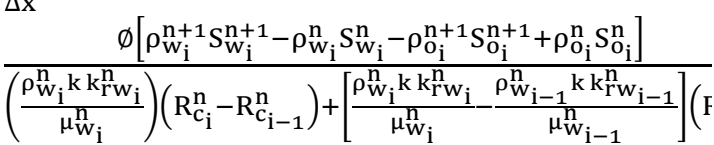

$$
\text { Assume, } \frac{\Delta t}{\Delta x}=\beta
$$

By the fraction $\beta$ we can make the suitable grid size we can make the equation stable by the select proper parameter of time and length.
Now simplify our equation,

$$
\begin{aligned}
& \left(\frac{\rho_{\mathrm{w}_{\mathrm{i}}}^{\mathrm{n}} \mathrm{k} \mathrm{k}_{\mathrm{rw}}^{\mathrm{n}}}{\mu_{\mathrm{w}_{\mathrm{i}}}^{\mathrm{n}}}\right)\left(\frac{\mathrm{R}_{\mathrm{c}_{\mathrm{i}}}^{\mathrm{n}}}{\Delta \mathrm{x}}\right)- \\
& \left(\frac{\rho_{\mathrm{w}_{\mathrm{i}}}^{\mathrm{n}} \mathrm{k} \mathrm{k}_{\mathrm{r}}^{\mathrm{n}}}{\mu_{\mathrm{w}_{\mathrm{i}}}^{\mathrm{n}}}\right)\left(\frac{\mathrm{R}_{\mathrm{c}_{\mathrm{i}-1}}^{\mathrm{n}}}{\Delta \mathrm{x}}\right)+\frac{\rho_{\mathrm{w}_{\mathrm{i}}}^{\mathrm{n}} \mathrm{kk}_{\mathrm{r} \mathrm{w}_{\mathrm{i}}}^{\mathrm{n}}}{\mu_{\mathrm{w}_{\mathrm{i}}}^{\mathrm{n}}}\left(\frac{\mathrm{R}_{\mathrm{c}_{\mathrm{i}}}^{\mathrm{n}}}{\Delta \mathrm{x}}\right)- \\
& \frac{\rho_{\mathrm{w}_{\mathrm{i}-1}}^{\mathrm{n}} \mathrm{k} \mathrm{k}_{\mathrm{r}}^{\mathrm{n}} \mathrm{w}_{\mathrm{i}-1}}{\mu_{\mathrm{w}_{\mathrm{i}-1}}^{\mathrm{n}}}\left(\frac{\mathrm{R}_{\mathrm{c}_{\mathrm{i}}}^{\mathrm{n}}}{\Delta \mathrm{x}}\right)=\left(\frac{\emptyset}{\Delta \mathrm{t}}\right) \rho_{\mathrm{w}_{\mathrm{i}}}^{\mathrm{n}+1} S_{\mathrm{w}_{\mathrm{i}}}^{\mathrm{n}+1}- \\
& \left(\frac{\emptyset}{\Delta \mathrm{t}}\right) \rho_{\mathrm{w}_{\mathrm{i}}}^{\mathrm{n}} \mathrm{S}_{\mathrm{w}_{\mathrm{i}}}^{\mathrm{n}}-\left(\frac{\emptyset}{\Delta \mathrm{t}}\right) \rho_{\mathrm{o}_{\mathrm{i}}}^{\mathrm{n}+1} \mathrm{~S}_{\mathrm{o}_{\mathrm{i}}}^{\mathrm{n}+1}+ \\
& \left(\frac{\varnothing}{\Delta \mathrm{t}}\right) \rho_{\mathrm{o}_{\mathrm{i}}}^{\mathrm{n}} S_{\mathrm{o}_{\mathrm{i}}}^{\mathrm{n}}
\end{aligned}
$$

For incompressible flow, $q$ function of length and temperature can be eliminated from the original flow equations, resulting in a system of $(n-1)$ quasi-linear hyperbolic equations. And restrictions on the maximum value for $f^{\prime} j, t / f^{\prime} j, x$ have been derived which are based upon stability conditions. The numerical solution of such equations by explicit schemes has been discussed extensively. One can argue heuristically that such conditions apply to the above finite - difference equations in such a manner as to be more restrictive than the criterion derived above. There is some computational evidence to support this, for both incompressible and compressible flow.

Assume, with the

$$
\left(\frac{\rho_{\mathrm{w}_{\mathrm{i}}}^{\mathrm{n}} \mathrm{k} k_{\mathrm{r}_{\mathrm{i}}}^{\mathrm{n}}}{\mu_{\mathrm{w}_{\mathrm{i}}}^{\mathrm{n}}}\right)=\mathrm{E}, \frac{\rho_{\mathrm{w}_{\mathrm{i}-1}}^{\mathrm{n}} \mathrm{k} k_{\mathrm{r}_{\mathrm{i}-1}}^{\mathrm{n}}}{\mu_{\mathrm{w}_{\mathrm{i}-1}}^{\mathrm{n}}}=\mathrm{F}, \frac{\Delta t}{\Delta x}=\beta
$$

Where $\mathrm{E}$ and $\mathrm{F}$ both are constants.

By the factor $\beta$, we can make the suitable grid size with the help of proper step size of time and length for the stable solution of the partial differential equation.

So our equation will be,

$$
\begin{aligned}
& \mathrm{E} * \mathrm{R}_{\mathrm{c}_{\mathrm{i}}}^{\mathrm{n}}-\mathrm{E} * \mathrm{R}_{\mathrm{c}_{\mathrm{i}-1}}^{\mathrm{n}}+\mathrm{E} * \mathrm{R}_{\mathrm{c}_{\mathrm{i}}}^{\mathrm{n}}-\mathrm{F} * \\
& \mathrm{R}_{\mathrm{C}_{\mathrm{i}}}^{\mathrm{n}}=\left(\frac{\emptyset}{\beta}\right)\left(\rho_{\mathrm{w}_{\mathrm{i}}}^{\mathrm{n}+1} \mathrm{~S}_{\mathrm{w}_{\mathrm{i}}}^{\mathrm{n}+1}-\rho_{\mathrm{w}_{\mathrm{i}}}^{\mathrm{n}} \mathrm{S}_{\mathrm{w}_{\mathrm{i}}}^{\mathrm{n}}-\right. \\
& \left.\rho_{o_{i}}^{n+1} S_{o_{i}}^{n+1}+\rho_{o_{i}}^{n} S_{o_{i}}^{n}\right) \\
& 2 * \mathrm{E} * \mathrm{R}_{\mathrm{c}_{\mathrm{i}}}^{\mathrm{n}}-\mathrm{E} * \mathrm{R}_{\mathrm{c}_{\mathrm{i}-1}}^{\mathrm{n}}-\mathrm{F} * \mathrm{R}_{\mathrm{c}_{\mathrm{i}}}^{\mathrm{n}}= \\
& \left(\frac{\emptyset}{\beta}\right)\left(\rho_{\mathrm{w}_{\mathrm{i}}}^{\mathrm{n}+1} \mathrm{~S}_{\mathrm{w}_{\mathrm{i}}}^{\mathrm{n}+1}-\rho_{\mathrm{w}_{\mathrm{i}}}^{\mathrm{n}} \mathrm{S}_{\mathrm{w}_{\mathrm{i}}}^{\mathrm{n}}-\right. \\
& \left.\rho_{o_{i}}^{n+1} S_{O_{i}}^{n+1}+\rho_{o_{i}}^{n} S_{o_{i}}^{n}\right) \\
& \mathrm{R}_{\mathrm{c}_{\mathrm{i}}}^{\mathrm{n}}(2 * \mathrm{E}-\mathrm{F})-\mathrm{E} * \mathrm{R}_{\mathrm{C}_{\mathrm{i}-1}}^{\mathrm{n}} \\
& =\left(\frac{\emptyset}{\beta}\right)\left(\rho_{\mathrm{w}_{\mathrm{i}}}^{\mathrm{n}+1} \mathrm{~S}_{\mathrm{w}_{\mathrm{i}}}^{\mathrm{n}+1}\right. \\
& -\rho_{\mathrm{w}_{\mathrm{i}}}^{\mathrm{n}} \mathrm{S}_{\mathrm{w}_{\mathrm{i}}}^{\mathrm{n}}-\rho_{\mathrm{O}_{\mathrm{i}}}^{\mathrm{n}+1} \mathrm{~S}_{\mathrm{O}_{\mathrm{i}}}^{\mathrm{n}+1} \\
& +\rho_{\mathrm{o}_{\mathrm{i}}}^{\mathrm{n}} S_{\mathrm{O}_{\mathrm{i}}}^{\mathrm{n}} \text { ) }
\end{aligned}
$$

Simplifying, this equation we arrived at the term with a value of $R_{c_{i}}$ for $n$th the degree. 
$\mathrm{R}_{\mathrm{C}_{\mathrm{i}}}^{\mathrm{n}}=\frac{\left(\frac{\emptyset}{\beta}\right)\left(\rho_{w_{i}}^{n+1} S_{w_{i}}^{n+1}-\rho_{w_{i}}^{n} S_{w_{i}}^{n}-\rho_{o_{i}}^{n+1} S_{o_{i}}^{n+1}+\rho_{o_{i}}^{n} S_{o_{i}}^{n}\right)+\mathrm{E} * \mathrm{R}_{\mathrm{c}_{\mathrm{i}-1}}^{\mathrm{n}}}{(2 * \mathrm{E}-\mathrm{F})}$ 2.34

Further, the equations for water saturation as variations in pressure gradient with respect to length and time are expressed below which tend to further modify and simplify as per the requirement.

$\mathrm{R}_{\mathrm{c}_{\mathrm{i}}}^{\mathrm{n}}(2 * \mathrm{E}-\mathrm{F})-\mathrm{E} * \mathrm{R}_{\mathrm{c}_{\mathrm{i}-1}}^{\mathrm{n}}=\left(\frac{\emptyset}{\beta}\right)\left(\rho_{\mathrm{w}_{\mathrm{i}}}^{\mathrm{n}+1} \mathrm{~S}_{\mathrm{w}_{\mathrm{i}}}^{\mathrm{n}+1}-\right.$ $\left.\rho_{w_{i}}^{n} S_{w_{i}}^{n}-\rho_{o_{i}}^{n+1} S_{o_{i}}^{n+1}+\rho_{o_{i}}^{n} S_{o_{i}}^{n}\right)$

$\left(\frac{\beta}{\emptyset}\right)\left(\mathrm{R}_{\mathrm{c}_{\mathrm{i}}}^{\mathrm{n}}(2 * \mathrm{E}-\mathrm{F})-\mathrm{E} * \mathrm{R}_{\mathrm{c}_{\mathrm{i}-1}}^{\mathrm{n}}\right)=\rho_{\mathrm{w}_{\mathrm{i}}}^{\mathrm{n}+1} \mathrm{~S}_{\mathrm{w}_{\mathrm{i}}}^{\mathrm{n}+1}-$ $\rho_{w_{i}}^{n} S_{w_{i}}^{n}-\rho_{o_{i}}^{n+1} S_{o_{i}}^{n+1}+\rho_{o_{i}}^{n} S_{o_{i}}^{n}$

After this step size resulting to more simple in solving, water saturation with $(n+1)$ th degree of factor we substitute the value of above equation.

$\rho_{\mathrm{w}_{\mathrm{i}}}^{\mathrm{n}+1} S_{\mathrm{w}_{\mathrm{i}}}^{\mathrm{n}+1}=\rho_{\mathrm{w}_{\mathrm{i}}}^{\mathrm{n}} S_{\mathrm{w}_{\mathrm{i}}}^{\mathrm{n}}+\rho_{\mathrm{o}_{\mathrm{i}}}^{\mathrm{n}+1} S_{\mathrm{o}_{\mathrm{i}}}^{\mathrm{n}+1}-\rho_{\mathrm{o}_{\mathrm{i}}}^{\mathrm{n}} S_{\mathrm{o}_{\mathrm{i}}}^{\mathrm{n}}+$ $\left(\frac{\beta}{\emptyset}\right)\left(\mathrm{R}_{\mathrm{C}_{\mathrm{i}}}^{\mathrm{n}}(2 * \mathrm{E}-\mathrm{F})-\mathrm{E} * \mathrm{R}_{\mathrm{c}_{\mathrm{i}-1}}^{\mathrm{n}}\right)$

After simplifying we obtained the equation for the Saturation with respect to parameters such as time and length.

$$
\begin{array}{|l}
\mathrm{S}_{\mathrm{w}_{\mathrm{i}}}^{\mathrm{n}+1}= \\
\frac{\rho_{\mathrm{w}_{\mathrm{i}}}^{\mathrm{n}} \mathrm{S}_{\mathrm{w}_{\mathrm{i}}}^{\mathrm{n}}+\rho_{\mathrm{O}_{\mathrm{i}}}^{\mathrm{n}+1} S_{\mathrm{O}_{\mathrm{i}}}^{\mathrm{n}+1}-\rho_{\mathrm{O}_{\mathrm{i}}}^{\mathrm{n}} \mathrm{S}_{\mathrm{O}_{\mathrm{i}}}^{\mathrm{n}}+\left(\frac{\beta}{\phi}\right)\left(\mathrm{R}_{\mathrm{c}_{\mathrm{i}}}^{\mathrm{n}}(2 * \mathrm{E}-\mathrm{F})-\mathrm{E} * \mathrm{R}_{\mathrm{c}_{\mathrm{i}-1}}^{\mathrm{n}}\right)}{\rho_{\mathrm{w}_{\mathrm{i}}}^{\mathrm{n}+1}}
\end{array}
$$

Here, we have the equation for the water saturation and pressure distribution with respect to time and length.

\subsection{Stability condition}

$$
\begin{gathered}
\begin{array}{c}
(2 * \mathrm{E}-\mathrm{F}) * \mathrm{R}_{\mathrm{c}_{\mathrm{i}}}^{\mathrm{n}}-\mathrm{E} * \mathrm{R}_{\mathrm{c}_{\mathrm{i}-1}}^{\mathrm{n}} \\
=\left(\frac{\emptyset}{\beta}\right)\left(\rho_{\mathrm{w}_{\mathrm{i}}}^{\mathrm{n}+1} S_{\mathrm{w}_{\mathrm{i}}}^{\mathrm{n}+1}-\rho_{\mathrm{w}_{\mathrm{i}}}^{\mathrm{n}} \mathrm{S}_{\mathrm{w}_{\mathrm{i}}}^{\mathrm{n}}\right. \\
\left.-\rho_{\mathrm{O}_{\mathrm{i}}}^{\mathrm{n}+1} S_{\mathrm{O}_{\mathrm{i}}}^{\mathrm{n}+1}+\rho_{\mathrm{o}_{\mathrm{i}}}^{\mathrm{n}} S_{\mathrm{O}_{\mathrm{i}}}^{\mathrm{n}}\right)
\end{array} \\
\mathrm{R}_{\mathrm{c}_{\mathrm{i}}}^{\mathrm{n}}=\frac{\emptyset *\left(\rho_{\mathrm{w}_{\mathrm{i}}}^{\mathrm{n}+1} S_{\mathrm{w}_{\mathrm{i}}}^{\mathrm{n}+1}-\rho_{\mathrm{w}_{\mathrm{i}}}^{\mathrm{n}} \mathrm{w}_{\mathrm{w}_{\mathrm{i}}}^{\mathrm{n}}-\rho_{\mathrm{o}_{\mathrm{i}}}^{\mathrm{n}+1} S_{\mathrm{o}_{\mathrm{i}}}^{\mathrm{n}+1}+\rho_{\mathrm{o}_{\mathrm{i}}}^{\mathrm{n}} S_{\mathrm{o}_{\mathrm{i}}}^{\mathrm{n}}\right)+\beta * \mathrm{E} * \mathrm{R}_{\mathrm{c}_{\mathrm{i}-1}}^{\mathrm{n}}}{\beta *(2 * \mathrm{E}-\mathrm{F})} \\
\mathrm{R}_{\mathrm{c}_{\mathrm{i}}}^{\mathrm{n}} \text { will be negative if and only if, }
\end{gathered}
$$

$\beta \geq \frac{\emptyset *\left(\rho_{\mathrm{w}_{\mathrm{i}}}^{\mathrm{n}} S_{\mathrm{w}_{\mathrm{i}}}^{\mathrm{n}}-\rho_{\mathrm{w}_{\mathrm{i}}}^{\mathrm{n}+1} S_{\mathrm{w}_{\mathrm{i}}}^{\mathrm{n}+1}+\rho_{\mathrm{o}_{\mathrm{i}}}^{\mathrm{n}+1} S_{\mathrm{o}_{\mathrm{i}}}^{\mathrm{n}+1}-\rho_{\mathrm{o}_{\mathrm{i}}}^{\mathrm{n}} S_{\mathrm{o}_{\mathrm{i}}}^{\mathrm{n}}\right)}{\beta *(2 * \mathrm{E}-\mathrm{F})}$

This restriction on $\beta$ can be removed by approximately the time derivative in the equation.

This approximation neglects the change in density over a given time step, which can be important for some problems. The finite difference formulation still allows for a spatial variation in the density, however, so that the problem is not quite that of strictly incompressible flow. Density distribution can vary from one time step to another as the pressure changes. In this sense, change in density with time is treated as a succession of steady states.

And $\beta$ is always greater than zero, providing $R_{c_{i}}^{n}$ is finite. Since the requirement that $S_{\mathrm{w}_{\mathrm{i}}}^{\mathrm{n}+1}$ be non-negative for all, implies that $S_{w_{i}}^{n+1}$ is bounded between zeros to unity.

For incompressible flow, $\mathrm{R}_{\mathrm{c}_{\mathrm{i}}}^{\mathrm{n}}$ can be eliminated from the original flow equation, resulting in a system of (n-1) quasilinear equation. The numerical solution of such equation be explicit scheme has been discussed extensively and restriction on the max value of $\beta$ be derived which are based upon stability condition. One can argue heuristically, that in such a manner as to be more restrictive, than the criterion derived above

\section{Result and Discussion}

The finite - difference methods presented above have been used to simulate several water flooding problems in laboratory-size cores. The table 1 (Byron et.al, 1966) gives a description of the problem and list of numerical values for input. The pressure as well as water saturation from above input parameter are calculated from the equation 2.34 and 2.35 for 8 hours, 16 hours, 32 hours, 48 hours and 96 hours for pressure and water saturation respectively as shown in the figure 1 and figure 2 .

After observing it so accurately, we came to note that as the time increases, simultaneously the pressure distribution range decreases for different lengths we considered.

On contrary to the results obtained for the parameter (pressure distribution), water saturation experiments, we noticed that gradually with fluctuation in time two changes are seen. Firstly when the time changes from 48 hours to 96 hours for the initial condition at the point itself starting from 0 the water saturation remains same. But for other readings of experiments when we took several readings of length $(\mathrm{x})$ in $\mathrm{ft}$, initially from 48 to 96 hours value increases and then gradually it decreases 
consistently for 32 hours and 16 hours respectively. Here in all cases, initial values are constant with $0.14 \mathrm{ft}$.

\subsection{Two-Phase Flow}

The finite - difference methods have been used to simulate several water flooding problems in laboratorysize cores. Both two-phase (water displacing oil) and three-phase (water displacing oil and gas) problems were considered. Computed pressure distributions for the two-phase case are shown at various times in figure1. Notice that the largest pressure gradients occur in the region of high oil saturation (or low water saturation), as expected. The inlet pressure decreases linearly with time during the first 44 hours, until breakthrough of the water-oil interface; after breakthrough, the inlet pressure declines less rapidly.

The figure 2 shows predicted water saturation profiles at various times for the two-phase case. A distinct wateroil interface moves through the system with a velocity of $1.6 \mathrm{ftlD}$ and a frontal water saturation of about 0.41 . These results agree favourably with the predictions of the Buckley-Leverett method 13 which yield a water-oil interface velocity of $1.62 \mathrm{ftlD}$ and a frontal water saturation of 0.405 . Agreement between the numerical solution and the Buckley-Leverett solution is to be expected since the Buckley-Leverett theory applies specifically to the case of the two-phase flow of incompressible fluids.

\section{Conclusions}

The finite-difference schemes developed here are of about the same order accuracy can be used to solve twophase water flooding problems. The implicit method requires 15 to 20 percent more machine time but generally allows the use of a larger time step for a given mesh spacing.

When applied to the displacement of oil by water in a linear, laboratory-size system, a sharp water-oil interface is propagated through the system with a constant velocity. The computed interface velocity and frontal water saturation are in excellent agreement with predictions of the Buckley-Leverett theory. If the system initially contains three phases (i.e., oil, water, and gas), an oil-gas interface is propagated through the system, followed by a water-oil interface. An oil bank forms between the interfaces positions, characterized by a constant oil saturation which is considerably greater than the initial oil saturation.

When initial water saturation is increased at the expense of the initial oil saturation (with the initial gas saturation held constant), the water-oil interface velocity increases, causing the oil bank to grow less rapidly. Eventually, the initial oil saturation becomes sufficiently low so that an oil bank cannot form. Now the oil saturation remains approximately equal to its initial value and a water-gas interface travels through the system. When used in the same manner as in the earlier problems, the BuckleyLeverett theory reveals whether or not an oil bank can form, as the predicted water-oil interface velocity may exceed the oil-gas interface velocity. In this case, the Buckley-Leverett theory will accurately predict the water-gas interface velocity and the frontal water saturation if it is assumed that water displaces gas with the oil saturation held constant.

\section{Nomenclature}

$S_{o}=$ Oil saturation

$S_{g}=$ Gas saturation

$S_{w}=$ Water saturation

$\sigma_{S o}=$ Interfacial tension between the solid and the

lighter fluid phase

$\sigma_{s w}=$ Interfacial tension between the solid and the denser fluid phase

$\theta_{O W}=$ Contact angle between oil and water

$P_{o}=$ Oil pressure, psia

$P_{w}=$ Water pressure, $\mathrm{psia}$

$\rho_{o}=$ Density of oil, $\mathrm{lb} / \mathrm{cu} \mathrm{ft}$

$\rho_{w}=$ Density of water, $\mathrm{lb} / \mathrm{cu} \mathrm{ft}$

$\mathrm{g}=$ Gravitational constant

$P_{\text {CoW }}=$ Oil-water capillary pressure

$N_{c}=$ capillary number

$\mu=$ fluid viscosity, $\mathrm{cp}$

$\mathrm{v}=$ flow velocity, $\mathrm{ft} / \mathrm{D}$

$\sigma=$ interfacial tension

$\varnothing=$ porosity in fraction

$\mathrm{Q}=$ volumetric flow rate, $\mathrm{cu} \mathrm{ft} / \mathrm{D}$

$\Delta \mathrm{p}=$ applied pressure drop across the sample, psia

$\mathrm{K}=$ relative permeability

$\mathrm{A}=$ cross section area, $\mathrm{sq} \mathrm{ft}$

$\mathrm{p}_{\mathrm{c}}=$ Capillary pressure, $\mathrm{psi}$

$\mathrm{K}_{\mathrm{n}}=$ Permeability for nonwetting phase

$\mathrm{K}_{\mathrm{W}}=$ Permeability for wetting phase

$\mathrm{k}_{\mathrm{rn}}=$ Relative permeability for nonwetting phase

$\mathrm{k}_{\mathrm{rw}}=$ Relative permeability for wetting phase

$\mathrm{D}=$ depth, $\mathrm{ft}$

$\alpha=$ geometric factor,

$\gamma=$ Constant

$\mathrm{G}=$ inlet mass, $\mathrm{lb} / \mathrm{hr}$, sq $\mathrm{ft}$

$\mathrm{L}=$ system length, $\mathrm{ft}$

$\mathrm{n}=$ number of flowing phases

$\mathrm{t}=$ time, hours

$\Delta \mathrm{t}=$ time step, hours

$\mathrm{X}=$ distance, $\mathrm{ft}$

$\Delta \mathrm{x}=$ mesh spacing, $\mathrm{ft}$

$\beta=\Delta \mathrm{t} / \Delta \mathrm{x}$, hours $/ \mathrm{ft}$ 


\section{References}

[1] Byron S. Gottfried, Guilinger, W.H. and Snyder, R. W., (1966). Numerical Solutions of the Equations for One-Dimensional Multi-Phase Flow in Porous Media. Society of petroleum engineers journals, 6, $62-72$

[2] Douglas, J., Jr., Blair, P.M. and Wagner, R. J. (1958). Calculation of Linear Waterflood Behavior Including the Effects of Capillary Pressure, Trans., AIME, 213, 96 - 102.
[3] Hanaa M. Farghally, Ninet M. Ahmed, Abd El Shafy A. Nafeh, Faten H. Fahmy, Amal A. Hassan, Emaad A. Sweelem (2020). Water from Air Production System based on Solar Energy in Egypt, International Journal of Mechanics, 14, 215-225.

[4] Gabriella Graziuso, Simona Mancini, Claudio Guarnaccia (2020). Comparison of Single Vehicle Noise Emission Models in Simulations and in a Real Case Study by Means of Quantitative Indicators, International Journal of Mechanics, 14, 198-207.

\section{Creative Commons Attribution License 4.0 (Attribution 4.0 International, CC BY 4.0)}

This article is published under the terms of the Creative Commons Attribution License 4.0

https://creativecommons.org/licenses/by/4.0/deed.en_US

Table 1: Input parameters [1]

\begin{tabular}{|cc|}
\hline Input Parameters & Value \\
\hline Number of phases & 2 \\
Porosity $(\varnothing)$ & $0.14(14 \%)$ \\
Initial Water saturation $\left(S_{w}\right)$ & 0.25 \\
Initial oil saturation $\left(S_{o}\right)$ & 0.75 \\
Inlet mass of water $(\mathrm{G})$ & $0.218 \mathrm{lb} / \mathrm{hr}$ sq. Feet \\
$\Delta t$ & $0.05 \mathrm{hrs}$ \\
$\Delta x$ & $0.025 \mathrm{feet}$ \\
B & $2.0 \mathrm{hr} / \mathrm{feet}$ \\
Length $(\mathrm{x})$ & $6.0 \mathrm{feet}$ \\
Pressure $(\mathrm{P})$ & $14.7 \mathrm{psi}$ \\
The density of water $\left(\rho_{w}\right)$ & $62.4 \mathrm{lb} / \mathrm{cu} \mathrm{ft}$ \\
The density of oil $\left(\rho_{o}\right)$ & $55.0 \mathrm{lb} / \mathrm{cu} \mathrm{ft}$ \\
Viscosity of water $\left(\mu_{\mathrm{w}}\right)$ & $0.8 \mathrm{cp}$ \\
The viscosity of oil $\left(\mu_{\mathrm{o}}\right)$ & $265 \mathrm{cp}$ \\
Permeability $(\mathrm{k})$ & $0.2637(\mathrm{sq} \mathrm{ft})(\mathrm{cp}) /(\mathrm{hr})(\mathrm{psi})$ \\
\hline
\end{tabular}




\section{List of captions for figures:}

Figure 1: Pressure distribution vs Length

Figure 2: Water saturation vs Length

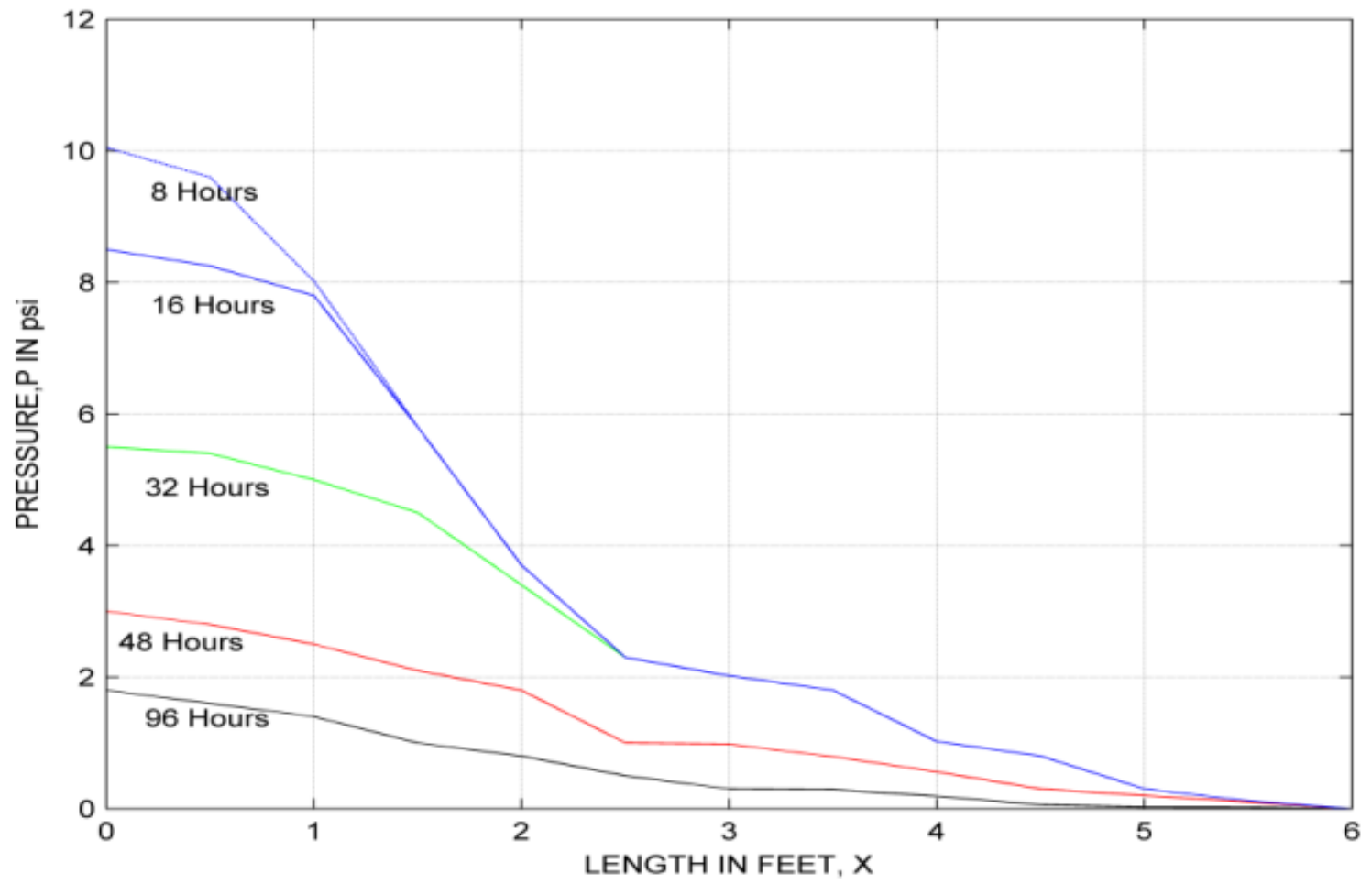

Figure 1

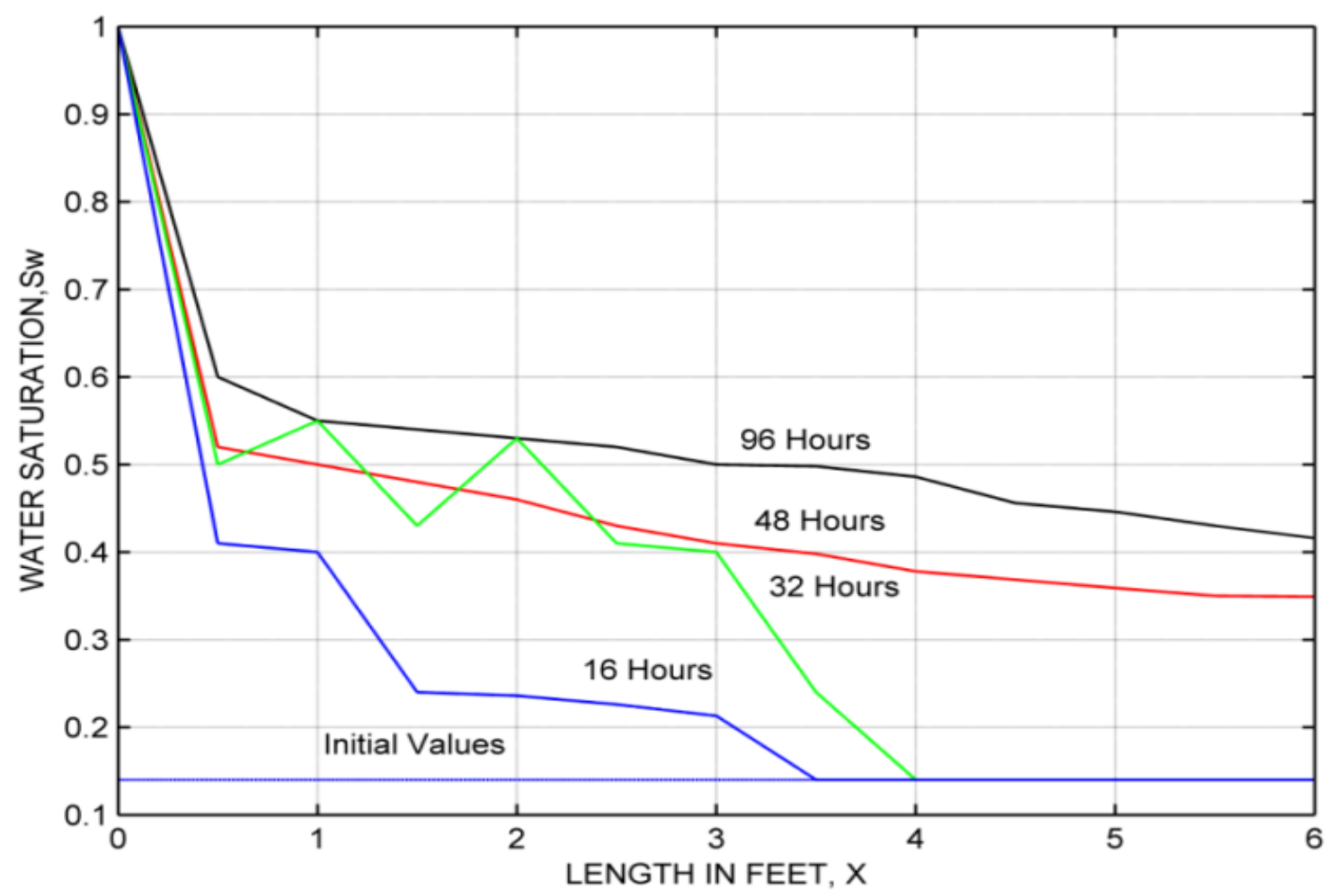

Figure 2 